\title{
Electronically Tunable Triple-Input Single-Output Voltage-Mode Biquadratic Filter Implemented with Single Integrated Circuit Package
}

\author{
Natchanai Roongmuanpha, Taweepol Suesut, Worapong Tangsrirat* \\ School of Engineering, King Mongkut's Institute of Technology Ladkrabang (KMITL), Bangkok 10520, Thailand
}

\begin{tabular}{l} 
A R T I C L E I N F O \\
\hline Article history: \\
Received: 30 September, 2020 \\
Accepted: 31 January, 2021 \\
Online: 25 February, 2021 \\
\hline Keywords: \\
Commercially available IC \\
LT1228 \\
Voltage mode circuit \\
Biquadratic filter \\
\end{tabular}

\begin{tabular}{l} 
A B S T R A C T \\
\hline This article proposes a compact and simple design of electronically adjustable voltage-mode \\
biquadratic filter using fundamental active cell implemented on a single integrated circuit \\
(IC) package as LT1228. The proposed circuit having triple inputs and single output (TISO) \\
employs namely one resistor and two capacitors as the passive components. All the five \\
possible biquadratic filtering responses, namely low-pass (LP), band-pass (BP), high-pass \\
(HP), band-stop (BS) and all-pass (AP), are realized by the appropriate selection of the \\
relevant input signals. The pole angular frequency and the quality factor of the proposed \\
TISO filter are electronically tunable through the bias current of the IC chip LT1228. Non- \\
ideal effects and sensitivity performance are carried out. The theoretical results are \\
satisfactorily validated by both PSPICE simulation results and experimental measurements \\
using commercially available LT1228.
\end{tabular}

\section{Introduction}

Over the decade, analog filters always play a role in many important analog signal processing applications, i.e. communication systems, measurement and instrumentation systems, etc. Nowadays, the realization of an active analog filter using versatile active building blocks has been focused by many researchers due to many advantage features, such as simple circuitry, high linearity, and wide dynamic range. In the literature, many modern active electronic elements have been utilized in analog active filter design, such as current conveyor (CC) [1-7], differential difference current conveyor (DDCC) [8-12], differential voltage current conveyor (DVCC) [13-16], fully differential second-generation current conveyor (FDCCII) [17], current differencing buffered amplifier (CDBA) [18-20], current feedback operational amplifier (CFOA) [21-27], current follower transconductance amplifier (CFTA) [28-29], operational transconductance amplifier (OTA) [30-34], voltage differencing buffered amplifier (VDBA) [35-36], voltage differencing inverting buffered amplifier (VDIBA) [37], fully balanced voltage differencing buffered amplifier (FB-VDBA) [38], voltage differencing transconductance amplifier (VDTA) [39-41], and voltage differencing gain amplifier (VDGA) [42-44]. However, so many of them require at least two or more active elements for

\footnotetext{
*Corresponding Author: Worapong Tangsrirat, Email: worapong.ta@kmitl.ac.th This paper is an extended version from the proceedings of 2020 8th International Electrical Engineering Congress (iEECON) [45]
}

their realizations $[1-5,7,8,10,11,13,18-27,30-39,41,43,44]$. Moreover, the voltage-mode filters presented in [1-17, 19-29, 38, 42] need a large number of passive resistors, while the articles in $[1,4,16,22]$ also contain three passive capacitors. It is also to be emphasized that the realizations of [1-27] suffer from the lack of electronic tuning capability of their important parameters. Even though some similar works were developed by based on various active building blocks in either bipolar junction transistor or (BJT) or complementary metal oxide semiconductor (CMOS) technologies, they are not commercially available chips and reachable in general. Besides, the performances of the research developments in $[1-4,7-20,22,24,25,28-37,39-44]$ have been demonstrated through only simulation results.

In this communication, an electronically tunable voltage-mode biquadratic filter with three input and one output terminals (TISO) consisting of only single active IC package LT1228, one resistor and two capacitors is introduced. The proposed TISO filter can realize the five standard biquadratic filtering responses, namely low-pass (LP), band-pass (BP), high-pass (HP), band-stop (BS) and all-pass (AP), all at a single output terminal without modifying a circuit structure. It also provides an electronic adjustability of its pole angular frequency $\left(\omega_{o}\right)$ and quality factor $(Q)$ via the external bias current of the LT1228 IC chip. The theoretical propositions are confirmed by PSPICE simulations with LT1228's model parameters, and the simulated results corroborate the theory. In addition, all conclusions discussed in this work are also verified by 
the measurement results of an experimentally test circuit with a single IC package LT1228, and the experimental findings are found to be in agreement with the theoretical values.

\section{Description of IC Package LT1228}

Our design utilizes only one active cell of a commercially available IC LT1228 from Linear Technology Company [46]. An active cell LT1228 is internally a combination of an operational transconductance amplifier (OTA) and a current feedback operational amplifier (CFA) in 8-pin IC package, as demonstrated in Figure 1. This device has three high impedance input terminals ( $\mathrm{p}, \mathrm{n}$, and $\mathrm{z}$ ), and one low impedance output terminal (o). It provides the output current $i_{z}$ at intermediate terminal $\mathrm{z}$ which is the difference of two input voltages $v_{p}$ and $v_{n}\left(v_{p}-v_{n}\right)$ multiplied by transconductance gain $\left(g_{m}\right)$. An external impedance $Z_{z}$ is connected to the terminal $\mathrm{z}$, and the potential $v_{z}$ developed across $Z_{z}$ will transfer to the output voltage $v_{o}$ at the terminal o by the CFA. Its ideal terminal characteristics can be described as:

$$
\left[\begin{array}{l}
i_{p} \\
i_{n} \\
i_{z} \\
v_{o}
\end{array}\right]=\left[\begin{array}{cccc}
0 & 0 & 0 & 0 \\
0 & 0 & 0 & 0 \\
g_{m} & -g_{m} & 0 & 0 \\
0 & 0 & 1 & 0
\end{array}\right] \cdot\left[\begin{array}{l}
v_{p} \\
v_{n} \\
v_{z} \\
i_{o}
\end{array}\right] .
$$

Thanks to the LT1228 manufacturing, the $g_{m}$-value can be altered to the desired value through the external DC bias current $I_{B}$ by the following relation: [46]

$$
g_{m}=10 I_{B} .
$$

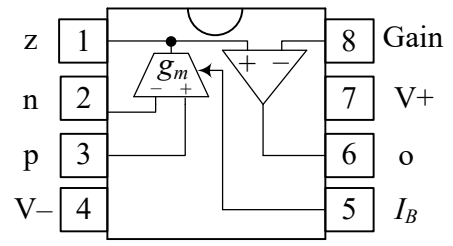

(a)

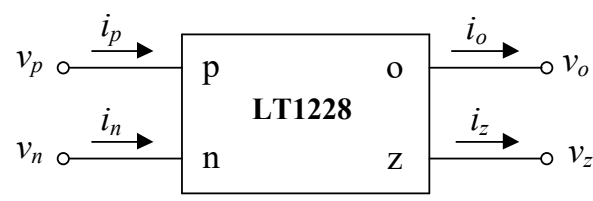

(b)

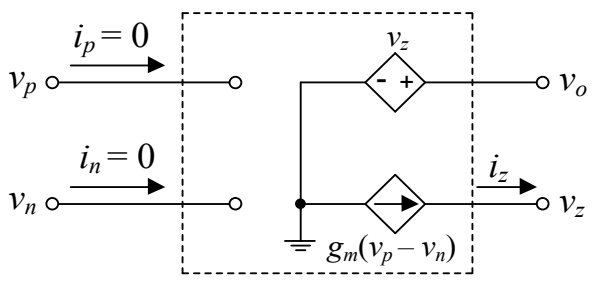

(c)

Figure 1: IC device LT1228

$\begin{array}{ll}\text { (a) active elements in LT1228 } & \text { (b) schematic representation }\end{array}$ (c) equivalent circuit.

\section{Proposed TISO Biquadratic Filter}

The realization of an electronically tunable TISO voltage-mode biquadratic filter is given in Figure 2. The proposed TISO filter is implemented with a single LT1228 together with one resistor and two capacitors. A straightforward analysis of the proposed TISO filter reveals the following output voltage function:

$$
V_{\text {out }}(s)=\frac{s^{2} R_{1} C_{1} C_{2} V_{3}+s C_{1} V_{2}+g_{m} V_{1}}{D(s)},
$$

where the denominator $D(s)$ is found to be:

$$
D(s)=s^{2} R_{1} C_{1} C_{2}+s C_{1}+g_{m} .
$$

From an inspection of Equations (3)-(4), it appears the five standard biquadratic filter functions can be obtained all at the terminal $v_{\text {out }}$ of the proposed circuit by the following conditions.

(i) The LP response is obtained by setting $v_{i n}=v_{1}$ (input voltage signal) and $v_{2}=v_{3}=0$ (grounded).

(ii) The BP response is obtained by setting $v_{i n}=v_{2}$ and $v_{1}=v_{3}=$ 0 .

(iii) The HP response is obtained by setting $v_{i n}=v_{3}$ and $v_{1}=v_{2}=$ 0 .

(iv) The BS response is obtained by setting $v_{i n}=v_{1}=v_{3}$ and $v_{2}=$ 0 .

(v) The AP response is obtained by setting $v_{i n}=v_{1}=-v_{2}=v_{3}$.

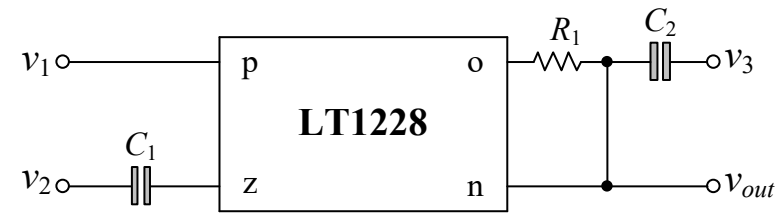

Figure 2: Proposed electronically tunable TISO biquad implementation employing single LT1228.

Therefore, the proposed TISO filter of Figure 2 does not require any element matching conditions or equality constraints for the desired filter function realizations. In all types, the important characteristics $\omega_{o}$, and $Q$ are respectively found as:

$$
\begin{aligned}
& \omega_{o}=2 \pi f_{o}=\sqrt{\frac{g_{m}}{R_{1} C_{1} C_{2}}}, \\
& \text { and } \\
& Q=\sqrt{\frac{g_{m} R_{1} C_{2}}{C_{1}}} .
\end{aligned}
$$

In case of practical design, if $C=C_{1}=C_{2}$, then the $\omega_{o}$ and $Q$ simplify to:

and

$$
\begin{gathered}
\omega_{o}=\frac{1}{C} \sqrt{\frac{g_{m}}{R_{1}}}, \\
Q=\sqrt{g_{m} R_{1}} .
\end{gathered}
$$

In view of the above expressions, the parameters $\omega_{o}$ and $Q$ of the proposed TISO filter can be altered electronically by means of $g_{m}$-value. According to Equation (2), the $g_{m}$ variation can be obtained by an adjustment of the bias current. Also note that since the major contribution of this work is to design a compact and 
minimum configuration voltage-mode TISO filter with electronic tunability, an orthogonal control of $\omega_{o}$ or $Q$ is not expected.

\section{Non-Ideal Analysis and Sensitivity Performance}

In consideration of the non-ideal behavior, the terminal behaviors of LT1228 can be rewritten as:

$$
\left[\begin{array}{l}
i_{p} \\
i_{n} \\
i_{z} \\
v_{o}
\end{array}\right]=\left[\begin{array}{cccc}
0 & 0 & 0 & 0 \\
0 & 0 & 0 & 0 \\
\alpha g_{m} & -\alpha g_{m} & 0 & 0 \\
0 & 0 & \beta & 0
\end{array}\right] \cdot\left[\begin{array}{l}
v_{p} \\
v_{n} \\
v_{z} \\
i_{o}
\end{array}\right],
$$

where $\alpha=\left(1-\varepsilon_{g m}\right)$ and $\beta=\left(1-\varepsilon_{v}\right)$, where $\left|\varepsilon_{g m}\right|<<1$ and $\left|\varepsilon_{v}\right|<<1$ are the transconductance inaccuracy and the voltage transfer error, respectively. Taking this effect into account, the characteristics $\omega_{o}$ and $Q$ given in Equations (5) and (6) are modified to:

$$
\omega_{o}=\sqrt{\frac{\alpha \beta g_{m}}{R_{1} C_{1} C_{2}}},
$$

$$
\text { and } \quad Q=\sqrt{\frac{\alpha \beta g_{m} R_{1} C_{2}}{C_{1}}} \text {. }
$$

In this case, all sensitivity coefficients of $\omega_{o}$ and $Q$ with respect to the active and passive components are derived and found to be as follows:

$$
\begin{gathered}
S_{\alpha}^{\omega_{o}}=S_{\beta}^{\omega_{o}}=S_{g_{m}}^{\omega_{o}}=\frac{1}{2}, \\
S_{R_{1}}^{\omega_{o}}=S_{C_{1}}^{\omega_{o}}=S_{C_{2}}^{\omega_{o}}=-\frac{1}{2}, \\
S_{\alpha}^{Q}=S_{\beta}^{Q}=S_{g_{m}}^{Q}=S_{R_{1}}^{Q}=S_{C_{2}}^{Q}=\frac{1}{2},
\end{gathered}
$$

$$
\text { and } \quad S_{C_{1}}^{Q}=-\frac{1}{2} .
$$

It is clear from Equations (12)-(15) that the absolute values of the $\omega_{0}$ - and $Q$-sensitivities are all equal to 0.5 . These values ensure that the sensitivity performance of the circuit is to be of low value.

\section{Simulation Results}

In this section, the proposed circuit and its filtering responses are simulated and discussed through the PSPICE simulation program. For ideal simulation, the LT1228 macro-model parameters obtained from Linear Technology Company and DC supply voltages of $\pm 5 \mathrm{~V}$ were employed. To demonstrate the functionality of the proposed filter, the circuit is designed for $f_{o}=$ $159.15 \mathrm{kHz}$ and $Q=1$. In this case, the various component values have been set as $I_{B}=100 \mu \mathrm{A}$ for $g_{m}=1 \mathrm{~mA} / \mathrm{V}, R_{1}=1 \mathrm{k} \Omega$ and $C_{1}$ $=C_{2}=1 \mathrm{nF}$. The simulation results for all filter responses are shown in Figures 3-7, which demonstrates very close agreement with the theoretical responses. For time-domain responses, a 159$\mathrm{kHz}$ sine-wave input voltage with $50 \mathrm{mV}$ peak amplitude was applied to the filter. The simulation results show that the error in $f_{o}$-value was found to be less than $1 \%$.

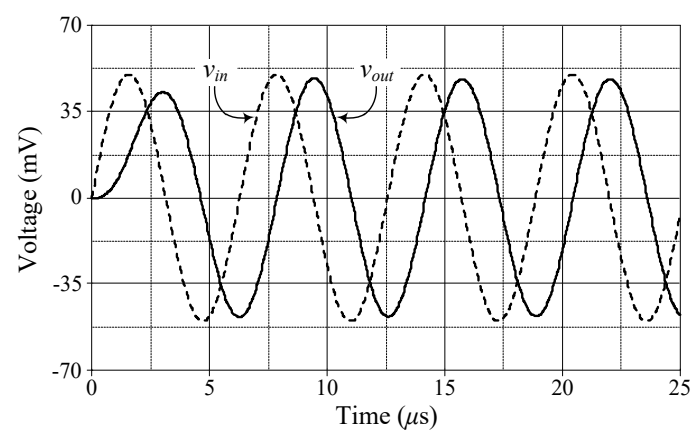

(a)

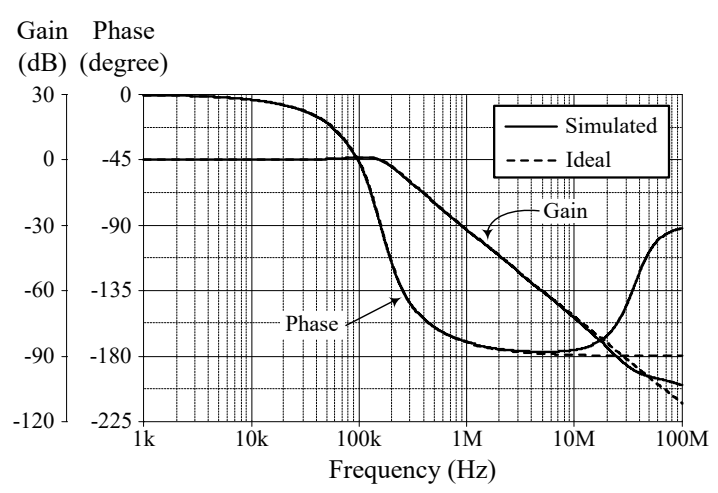

(b)

Figure 3: Ideal and simulated LP characteristics $\begin{array}{ll}\text { (a) time-domain responses } & \text { (b) frequency responses }\end{array}$

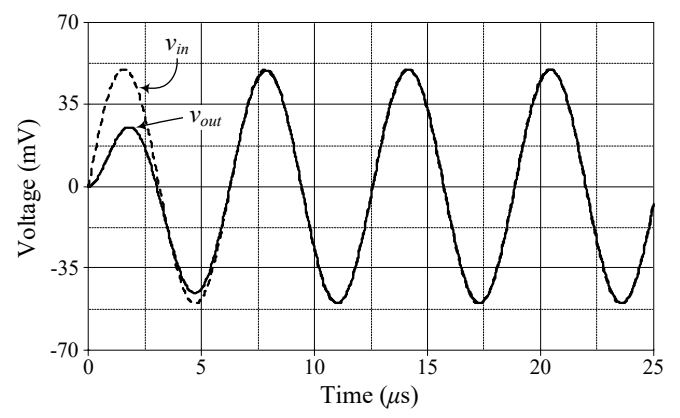

(a)

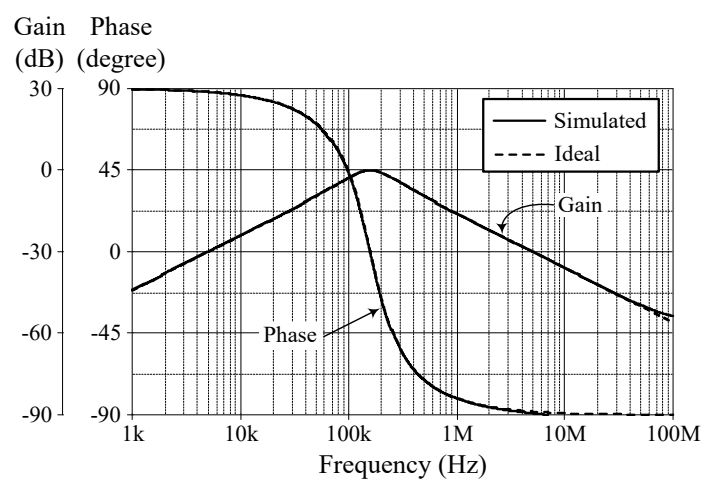

(b)

Figure 4: Ideal and simulated BP characteristics (a) time-domain responses (b) frequency responses 


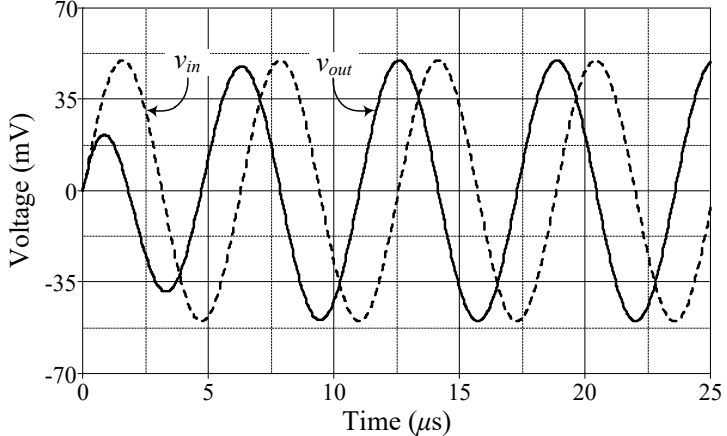

(a)

Gain Phase

(dB) (degree)

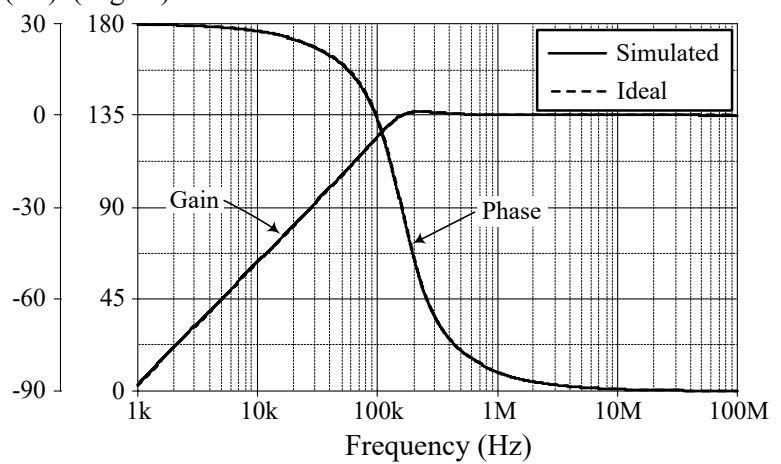

(b)

Figure 5: Ideal and simulated HP characteristics
(a) time-domain responses
(b) frequency responses

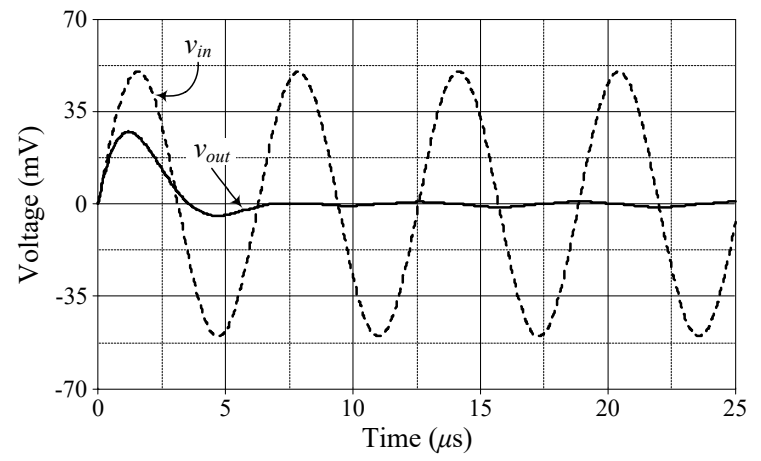

(a)

Gain Phase

(dB) (degree)

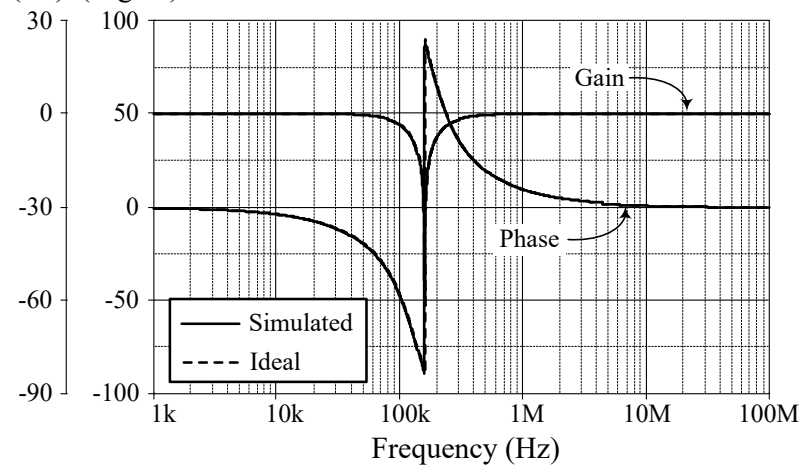

(b)

Figure 6: Ideal and simulated BS characteristics

$\begin{array}{ll}\text { (a) time-domain responses } & \text { (b) frequency responses }\end{array}$

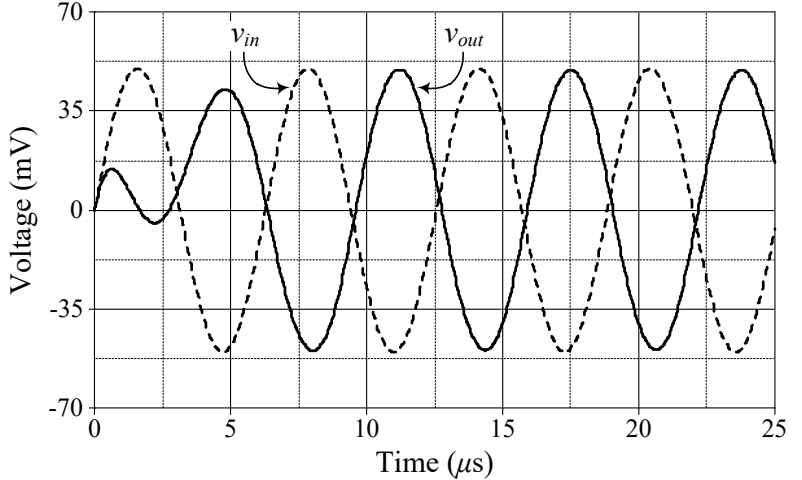

(a)

Gain Phase

(dB) (degree)

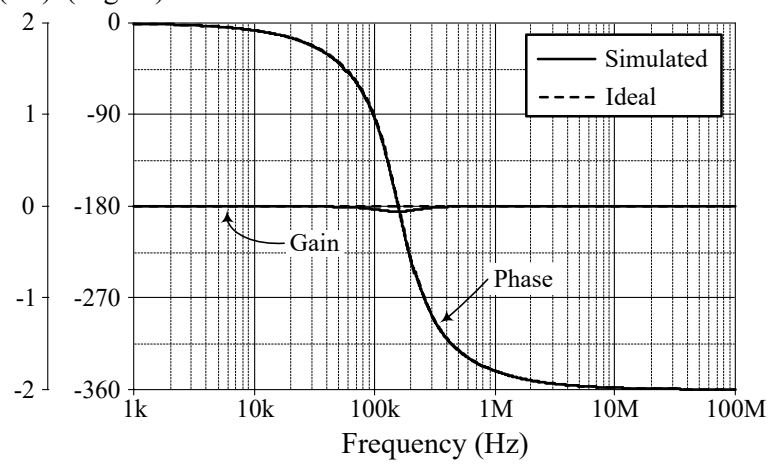

(b)

Figure 7: Ideal and simulated AP characteristics
(a) time-domain responses
(b) frequency responses

Furthermore, the electronic tuning of gain characteristic for BP filter concerning $I_{B}$ is observed. The related gain expressions of the proposed BP filter, as shown in Figure 8, are plotted for $I_{B}=50$ $\mu \mathrm{A}, 200 \mu \mathrm{A}$, and $500 \mu \mathrm{A}$, which resulted in $g_{m}=0.5 \mathrm{~mA} / \mathrm{V}, 2$ $\mathrm{mA} / \mathrm{V}$, and $5 \mathrm{~mA} / \mathrm{V}$, respectively. From Figure 8, the simulation conditions, and corresponding theoretical and simulated $f_{o}$ and $Q$ are summarized in Table 1.

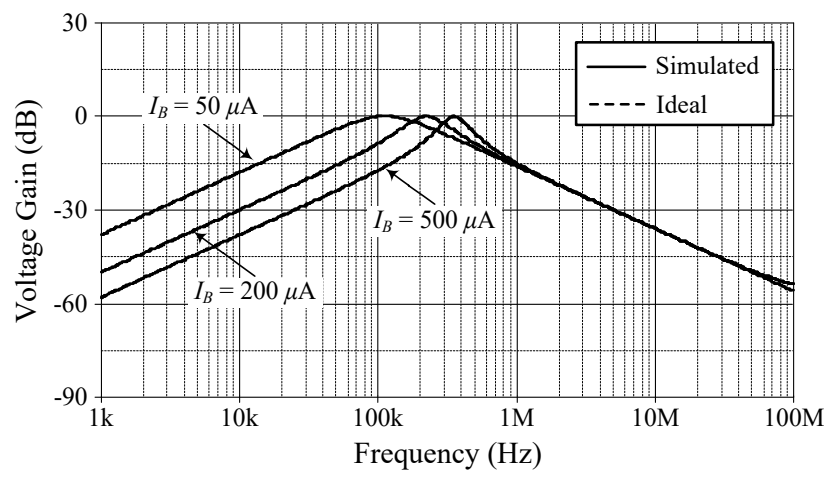

Figure 8: Ideal and simulated frequency responses of the proposed BP filter with an adjustment of $I_{B}$.

\section{Experimental Results}

To further validate the practical workability of the TISO biquadratic filter in Figure 2, the prototype circuit built with readily available IC element LT1228 and discrete passive elements were used to execute experimentally laboratory tests. The circuit was measured using Keysight EDUX1002G digital storage oscilloscope. All of the measured results were performed 
Table 1: $f_{o}$ and $Q$ adjustment of the proposed filter by varying $I_{B}$

\begin{tabular}{|c|c|c|c|c|c|c|c|}
\hline \multirow{2}{*}{$I_{B}(\mu \mathrm{A})$} & \multirow{2}{*}{$g_{m}(\mathrm{~mA} / \mathrm{V})$} & \multirow{2}{*}{$R_{1}(\mathrm{k} \Omega)$} & \multirow{2}{*}{$C(\mathrm{nF})$} & \multirow{2}{*}{$Q$} & \multicolumn{2}{|c|}{$f_{o}(\mathrm{kHz})$} & \multirow{2}{*}{$\% f_{o}$ deviation } \\
\hline & & & & & Simulated & Ideal & \\
\hline 50 & 0.5 & 1 & 1 & 0.7 & 111.43 & 112.54 & 0.99 \\
\hline 100 & 1 & 1 & 1 & 1 & 157.70 & 159.15 & 0.91 \\
\hline 200 & 2 & 1 & 1 & 1.4 & 222.84 & 225.08 & 0.99 \\
\hline 500 & 5 & 1 & 1 & 2.2 & 352.37 & 355.88 & 0.99 \\
\hline
\end{tabular}

at symmetrical supply voltages of $\pm 5 \mathrm{~V}$, and $I_{B}=100 \mu \mathrm{A}\left(g_{m}=1\right.$ $\mathrm{mA} / \mathrm{V}), R_{1}=1 \mathrm{k} \Omega$, and $C_{1}=C_{2}=1 \mathrm{nF}$. This results in $f_{o}=159.15$ $\mathrm{kHz}$ and $Q=1$. To observed transient response, the measurement was carried out with a $159-\mathrm{kHz}$ sine-wave signal input of $50 \mathrm{mV}$ peak amplitude. The experimental results for the transient and frequency responses as well as the associated frequency spectrums are displayed in Figures 9-13. Also from Figures 9(c)13(c), the measured results of the percentage total harmonic distortion (\%THD) of the $v_{\text {out }}$ for each filtering responses are noted in Table 2. It can be concluded that the measured results are close to the theoretical analysis, and also verify the functionality of the proposed circuit.

Table 2: Total harmonic distortions of $v_{\text {out }}$ in Figure 2.

\begin{tabular}{|c|c|}
\hline Filter & THD (\%) \\
\hline LP & 0.67 \\
\hline BP & 4.47 \\
\hline HP & 0.73 \\
\hline BS & 2.4 \\
\hline AP & 0.32 \\
\hline
\end{tabular}

Another set of measurements have been carried out to examine the electronic adjustability of the proposed TISO filter. BP filter response is used for illustrative purposes. Figure 14 illustrates the measured BP frequency responses for various bias current $I_{B}$. The $g_{m}$-values of the considered filter have been set as $0.5 \mathrm{~mA} / \mathrm{V}, 2$ $\mathrm{mA} / \mathrm{V}$, and $5 \mathrm{~mA} / \mathrm{V}$, for $I_{B}=50 \mu \mathrm{A}, 200 \mu \mathrm{A}$, and $500 \mu \mathrm{A}$, respectively. As follows from Equations (5) and (6), the $f_{o}$ values have been obtained as $112.54 \mathrm{kHz}, 225.08 \mathrm{kHz}$, and $355.88 \mathrm{kHz}$, while the $Q$ values have been obtained as $0.7,1.4$, and 2.2, respectively.

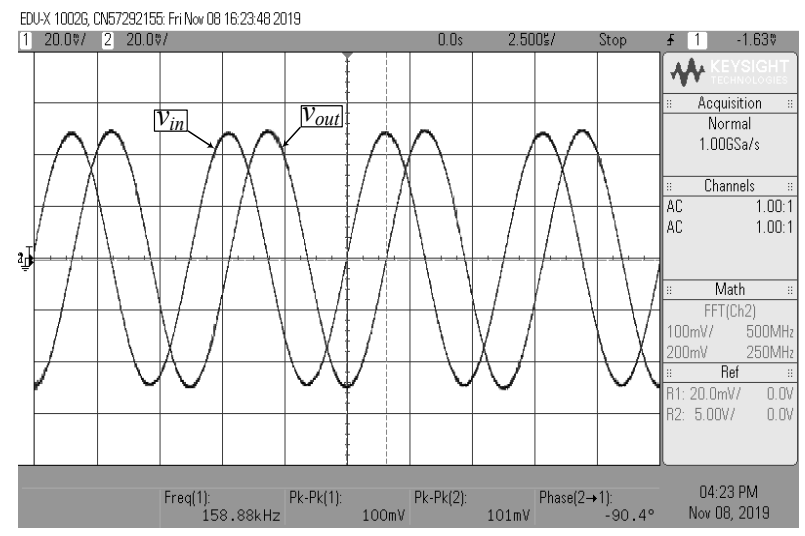

(a)

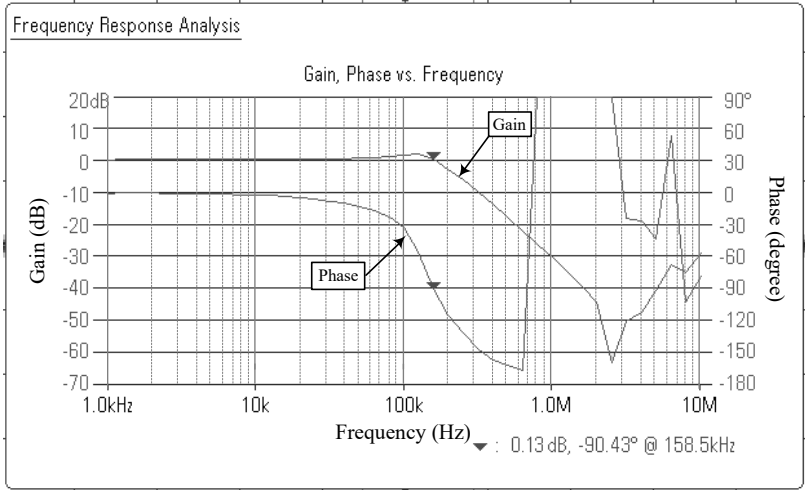

(b)

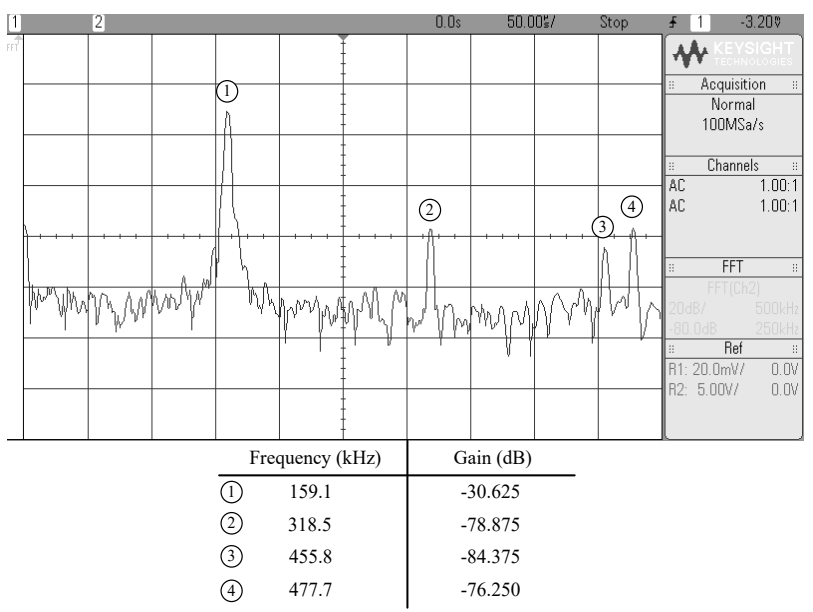

(c)

Figure 9: Experimental results of the proposed LP filter. $\begin{array}{ll}\text { (a) time-domain responses } & \text { (b) frequency responses }\end{array}$ (c) frequency spectrum

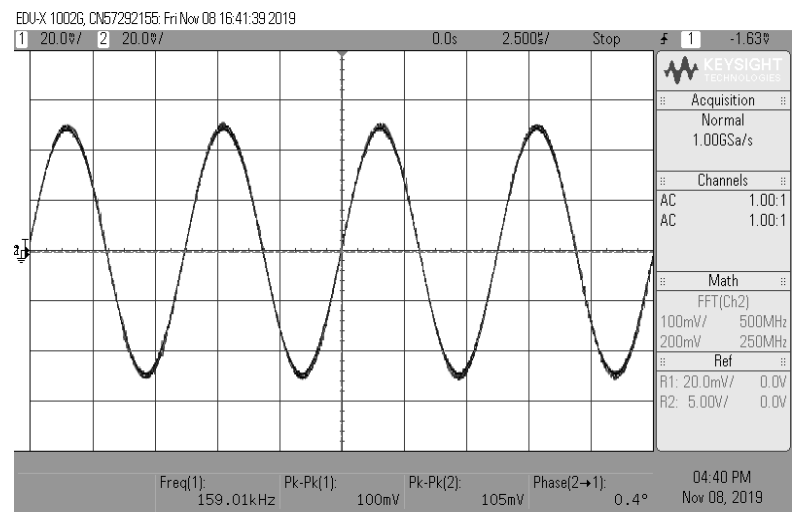

(a) 


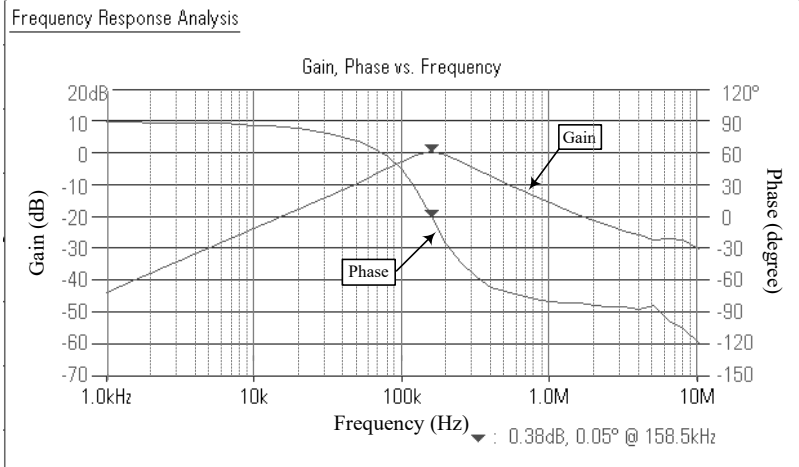

(b)

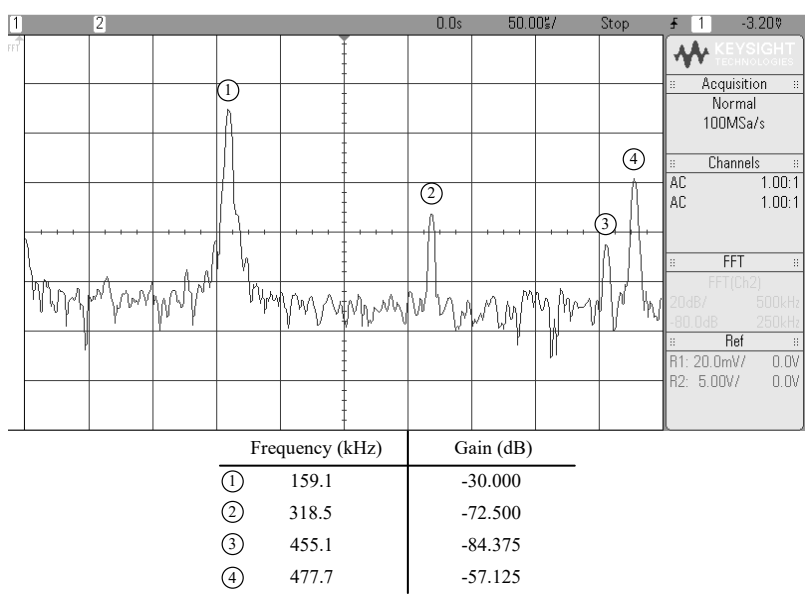

(c)

Figure 10: Experimental results of the proposed BP filter $\begin{array}{lll}\text { (a) time-domain responses } & \text { (b) frequency responses }\end{array}$ (c) frequency spectrum

EDU-X 10026, CNN7292215: FriNoor 08 17:04:492019

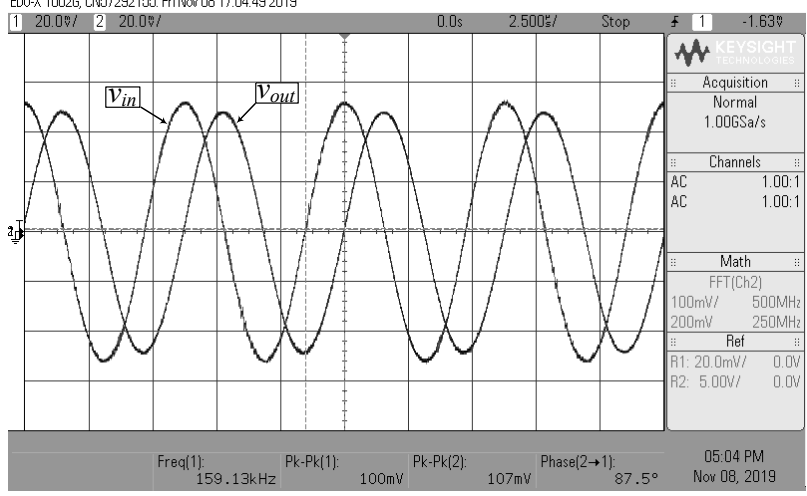

(a)

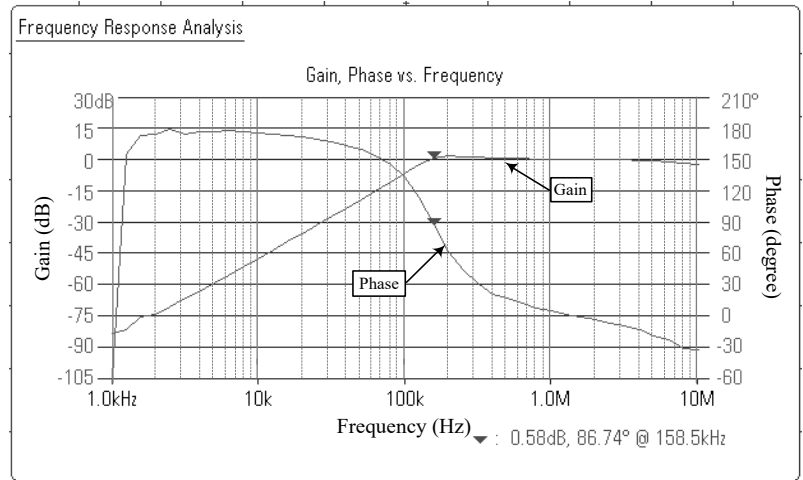

(b)

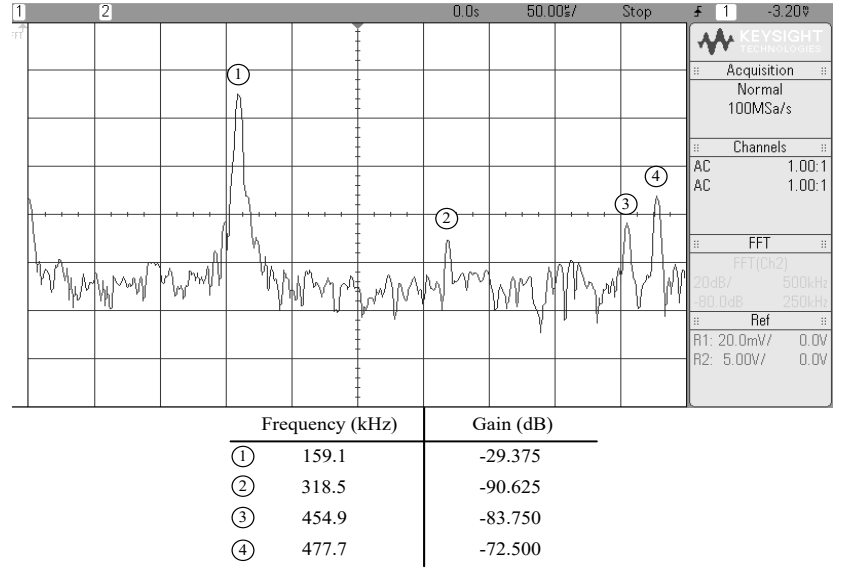

(c)

Figure 11: Experimental results of the proposed HP filter (a) time-domain responses (b) frequency responses (c) frequency spectrum

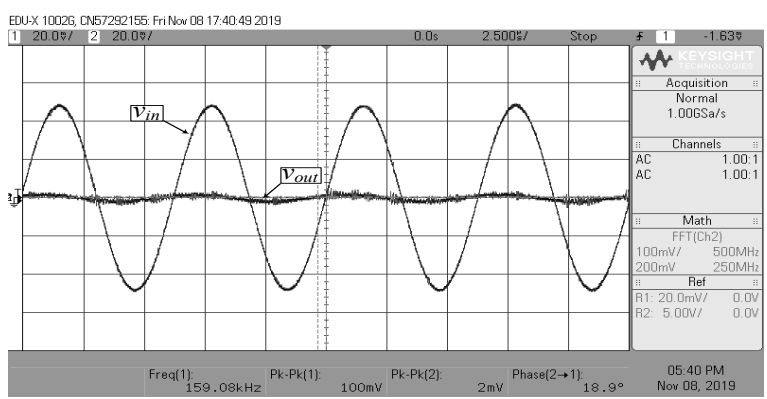

(a)

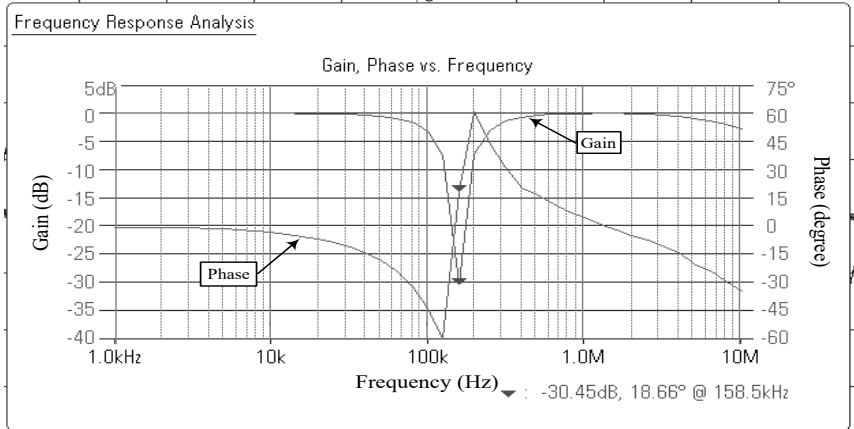

(b)

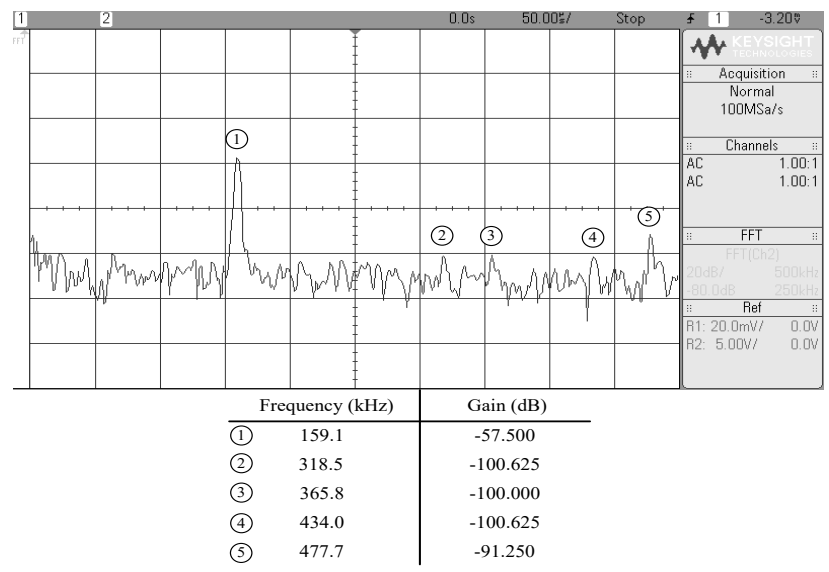

(c)

Figure 12: Experimental results of the proposed BS filter $\begin{array}{ll}\text { (a) time-domain responses (b) frequency responses } & \end{array}$ (c) frequency spectrum 


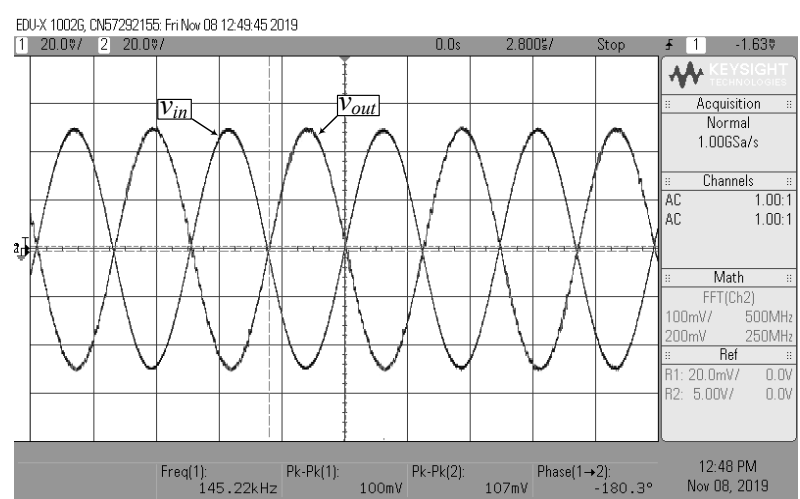

(a)

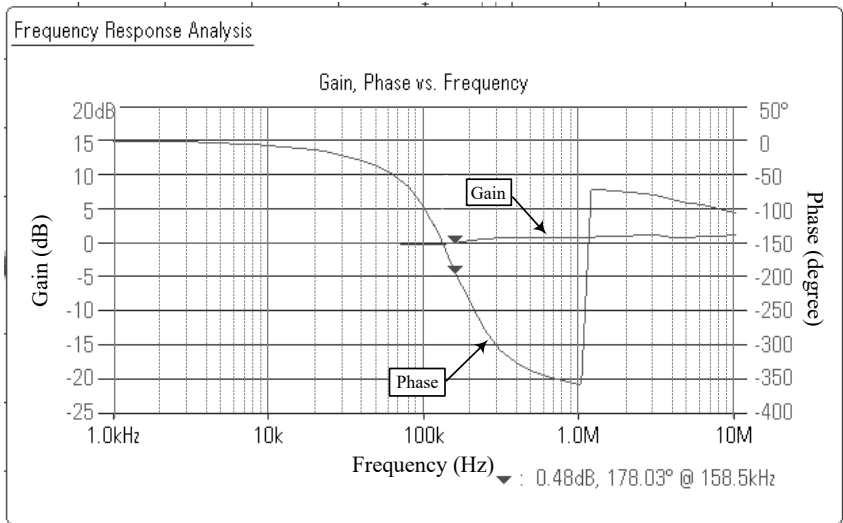

(b)

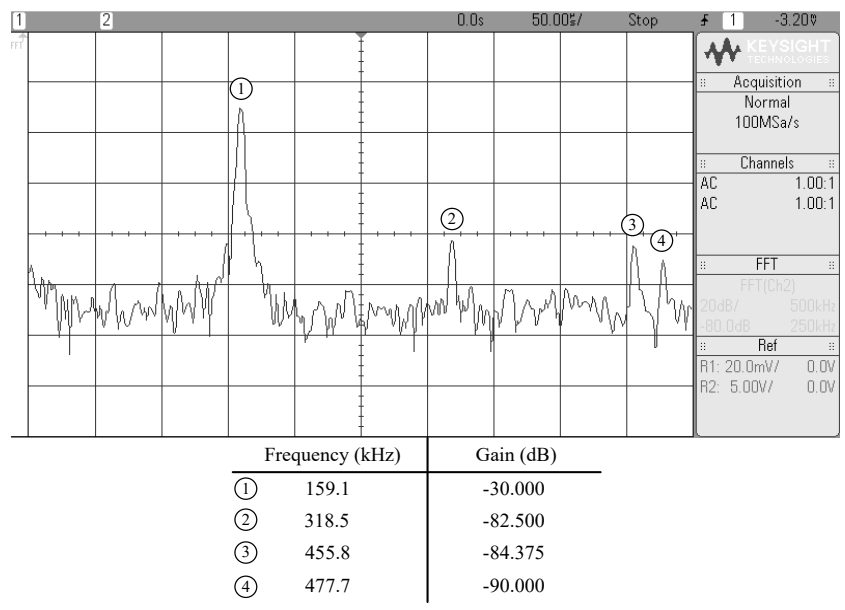

(c)

Figure 13: Experimental results of the proposed AP filter $\begin{array}{ll}\text { (a) time-domain responses } & \text { (b) frequency responses }\end{array}$ (c) frequency spectrum

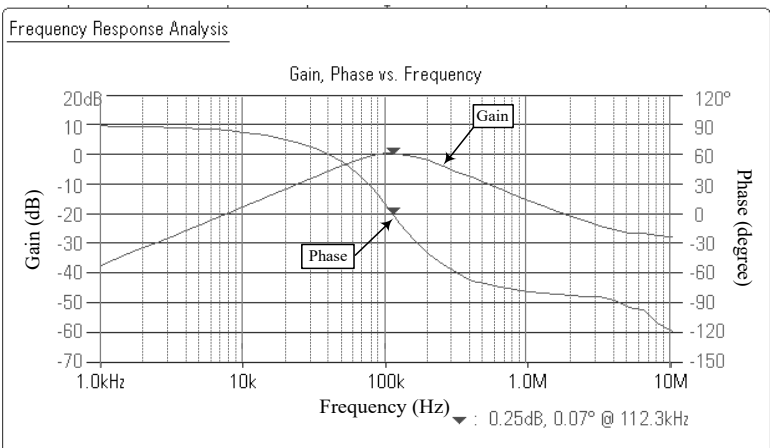

(a)

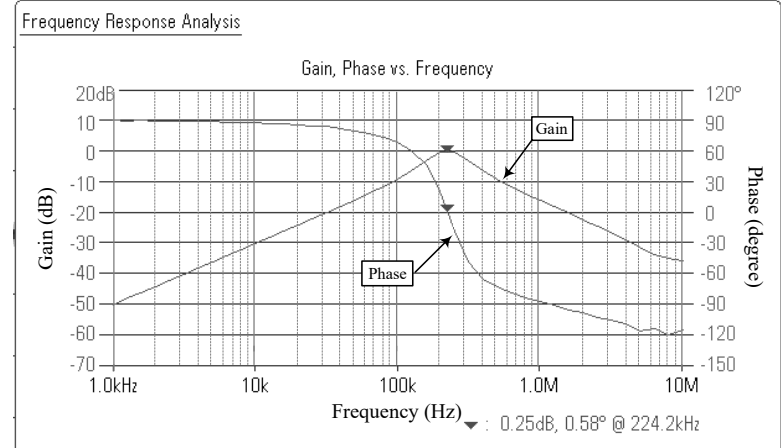

(b)

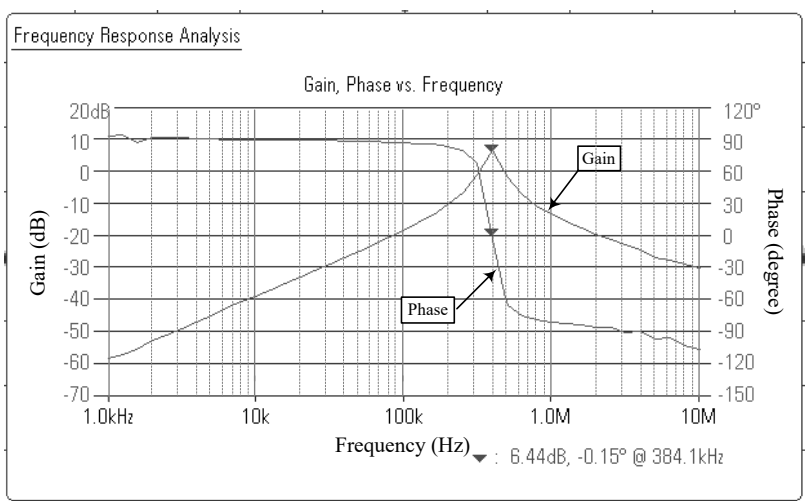

(c)

Figure 14: Measured gain responses for the proposed BP filter with an adjustment of $I_{B}$.
(a) $I_{B}=50 \mu \mathrm{A}$
(b) $I_{B}=200 \mu \mathrm{A}$
(c) $I_{B}=500 \mu \mathrm{A}$

\section{Conclusions}

This contribution describes the practical implementation of an electronically tunable voltage-mode biquadratic filter with triple input terminals and single output terminal. The proposed filter employs only a single commercially available IC LT1228 together with one resistor and two capacitors. The filter can realize all five standard biquadratic filtering functions all at a single output terminal by an appropriate input signal selection. The characteristics of $\omega_{o}$ and $Q$ can be controlled electronically and linearly in an electronic manner via the external bias current. Simulation results obtained from the PSPICE macro-model of the LT1228 by Linear Technology as well as constructed in prototype hardware using commercially available IC LT1228 are performed to confirm the properties of the proposed circuit.

\section{Conflict of Interest}

The authors declare that they have no conflict of interest.

\section{Acknowledgment}

This work was supported by the Faculty of Engineering, King Mongkut's Institute of Technology Ladkrabang (KMITL) under the contract number 2563-02-01-002.

\section{References}

[1] M. Higashimura, "Realisation of voltage-mode biquads using CCIIs"

$\begin{array}{lll}\text { M. Higashimura, "Realisation of voltage-mode biquads using } & \text { CClls" } \\ \text { Electron. } & \text { 27(15), } & 1345-1346,\end{array}$ https://doi.org/10.1049/el:19910847 
[2] A.M. Soliman, "Kerwin-Huelsman-Newcomb circuit using current conveyors" Electron. Lett., 30(24), 2019-2020, 1994. https://doi.org/10.1049/el:19941368

[3] M. Higashimura, Y. Fukui, "Universal filter using plus-type CCIIs" Electron. Lett., 32(9), 810-811, 1996. https://doi.org/10.1049/el:19960518

[4] J. W. Horng, J. R. Lay, C. W. Chang, M. H. Lee, "High input impedance voltage-mode multifunction filters using plus-type CCIIs" Electron. Lett., 33(6), 472-473, 1997. https://doi.org/10.1049/el:19970297

[5] C. M. Chang, M. J. Lee, "Voltage-mode multifunction filter with single input and three outputs using two compound current conveyors" IEEE Trans. Circuits Syst.-I: Fundamental Theory and Applications, 46(11), 1364-1365, 1999. https://doi.org/10.1109/81.802827

[6] J. W. Horng, "Voltage/current-mode universal biquadratic filter using single CCII+" Indian J. Pure \& Appl. Phys., 48(10), 749-756, 2010.

[7] J. W. Horng, Z. R. Wang, C. C. Liu, "Voltage-mode lowpass, bandpass and notch filters using three plus-type CCIIs" Circuits and Systems, 2(1), 34-37, 2011. https://doi.org/ 10.4236/cs.2011.21006

[8] J. W. Horng, W. Y. Chiu, H. Y. Wei, "Voltage-mode highpass, bandpass and lowpass filters using two DDCCs" Int. J. Electronics, 91(8), 461-464, 2004. https://doi.org/10.1080/00207210412331294603

[9] M. A. Ibrahim, H. Kuntman, O. Cicekoglu, "Single DDCC biquads with high input impedance and minimum number of passive elements" Analog Integr. Circ. Sig. Process., 43, 71-79, 2005. https://doi.org/10.1007/s10470-0056572-0

[10] W. Y. Chiu, J. W. Horng, "High-input and low-output impedance voltagemode universal biquadratic filter using DDCCs" IEEE Trans. Circuits Syst.II: Express Briefs, 54(8), 649-652, 2007. https://doi.org/10.1109/TCSII.2007.899460

[11] H. P. Chen, "Universal voltage-mode filter using only plus-type DDCCs" Analog Integr. Circ. Sig. Process., 50, 137-138, 2007. https://doi.org/10.1007/s10470-006-9005-9

[12] W. Y. Chiu, J. W. Horng, "Voltage-mode highpass, bandpass, lowpass and notch biquadratic filters using single DDCC" Radioengineering, 21(1), 297303, 2012.

[13] H. P. Chen, S. S. Shen, "A versatile universal capacitor-grounded voltagemode filter using DVCCs" ETRI Journal, 29(4), 470-476, 2007. https://doi.org/10.4218/etrij.07.0106.0335

[14] E. Yuce, "Voltage-mode multifunction filters employing a single DVCC and grounded capacitors", IEEE Trans. Instrum. Meas., 58(7), 2216-2221, 2009. https://doi.org/10.1109/tim.2009.2013671

[15] W. Tangsrirat, O. Channumsin, "Voltage-mode multifunctional biquadratic filter using single DVCC and minimum number of passive elements" Indian Journal Pure \& Applied Physics, 49(10), 703-707, 2011.

[16] J. W. Horng, "Voltage-mode multifunction bi-quadratic filter employing single DVCC”, Indian Journal Pure \& Applied Physics, 99(2), 153-162, 2012. https://doi.org/10.1080/00207217.2011.623268

[17] F. Kaçar, A. Yeşil, "Voltage mode universal filters employing single FDCCII" Analog Integr. Circ. Sig. Process., 63, 137-142, 2010. https://doi.org/10.1007/s10470-009-9440-5

[18] K. N. Salama, A. M. Soliman, "Voltage mode Kerwin-Huelsman-Newcomb circuit using CDBAs" Frequenz, 54(3-4), 90-93, 2000. https://doi.org/10.1515/FREQ.2000.54.3-4.90

[19] W. Tangsrirat, T. Pukkalanun, W. Surakampontorn, "CDBA-based universal biquad filter and quadrature oscillator" Active and Passive Electron. Components, 2008, (247171, 6 pages), 2008. https://doi.org/10.1155/2008/247171

[20] J. Pathak, A. K. Singh, R. Senani, "New voltage mode universal filters using only two CDBAs" ISRN Electronics, 2013(12), (987867, 6 pages), 2013. https://doi.org/10.1155/2013/987867

[21] S. I. Liu, D. S. Wu, "New current-feedback amplifier-based universal biquadratic filter" IEEE Trans. Instrum. Meas., 44(4), 915-917, 1995. https://doi.org/10.1109/19.392891

[22] J. W. Horng, M. H. Lee, "High input impedance voltage-mode lowpass, bandpass and highpass filter using current-feedback amplifiers" Electron. Lett., 33(11), 947-948, 1997. https://doi.org/10.1049/el:19970618

[23] J. W. Horng, "New configuration for realizing universal voltage-mode filter using two current feedback amplifiers" IEEE Trans. Instrum. Meas., 49(5), 1043-1045, 2000. https://doi.org/10.1109/19.872927

[24] N. Shah, M. F. Rather, S. Z. Iqbal, "CFA-based three input and two outputs voltage-mode universal filter” Indian J. Pure \& Appl. Phys., 43(8), 636-639, 2005.

[25] S. Topaloglu, M.Sagbas, F.Anday, "Three-input single-output second-order filters using current-feedback amplifiers" Int. J. Electron. Commun. (AEÜ), 66(8), 683-686, 2012. https://doi.org/10.1016/j.aeue.2011.12.009

[26] V. K. Singh, A. K. Singh, D. R. Bhaskar, R. Senani, "New universal biquads employing CFOAs" IEEE Trans. Circuits Syst.-II: Express Briefs, 53(11), 1299-1303, 2006. https://doi.org/10.1109/TCSII.2006.882345

[27] S. F. Wang, H. P. Chen, Y. Ku, P. Y. Chen, "A CFOA-based voltage-mode multifunction biquadratic filter and a quadrature oscillator using the CFOA- based biquadratic filter" Appl. Sci., 9(11), 2019 https://doi.org/10.3390/app9112304

[28] W. Tangsrirat, "Novel Current-mode and voltage-mode universal biquad filters using single CFTA" Indian Journal Pure \& Applied Physics., 17(2), 90 $104,2010$.

[29] J. Sirirat, W. Tangsrirat, W. Surakampontorn, "Voltage-mode electronically tunable universal filter employing single CFTA" in 2010 International Conference on Electrical Engineering/Electronics, Computer, Telecommunications and Information Technology (ECTI-CON), Chiang Mai, Thailand, 2010.

[30] R. Nawrocki, U. Klein, "New OTA-capacitor realisation of a universal biquad" Electron. $\quad$ Lett., 22(1), 50-51, 1986. https://doi.org/10.1049/el:19860034

[31] J. Wu, E. I. E. Masry, "Universal voltage- and current-mode OTAs based biquads" International Journal Electronics, 85(5), 553-560, 1998. https://doi.org/10.1080/002072198133842

[32] J. W. Horng, "Voltage-mode universal biquadratic filter using two OTAs" Active and Passive Elec. Comp., 27, 85-89, 2004 https://doi.org/10.1080/0882751031000116160

[33] M. Kumngern, M. Somdunyakanok, P. Prommee, "High-input impedance voltage-mode multifunction filter with three-input single-output based on simple CMOS OTAs" in 2008 International Symposium on Communications and Information Technologies (ISCIT), Lao, China, 2008 https://doi.org/10.1109/ISCIT.2008.4700228

[34] J. Sarasri, B. Knobnob, M. Kumngern, "Electronically tunable voltage-mode universal filter using simple OTAs" in 2011 IEEE International Conference on Computer Science and Automation Engineering (CSAE), Shanghai, China, 2011. https://doi.org/10.1109/CSAE.2011.5952912

[35] F. Kaçar, A. Yesil, A. Noori, "New CMOS realization of voltage differencing buffered amplifier and its biquad filter applications" Radioengineering, 21(1), 333-339, 2012

[36] J. Pimpol, N. Roongmuanpha, W. Tangsrirat, "Low-output-impedance electronically adjustable universal filter using voltage differencing buffered amplifiers" in 2019 International Conference on Informatics, Environment, Energy and Applications (IEEA), Osaka, Japan, 2019. https://doi.org/10.1145/3323716.3323738

[37] O. G. Sokmen, S. A. Tekin, H. Ercan, M. Alci, “A novel design of low-voltage VDIBA and filter application" Elektronika Ir Elektrotechnika, 22(6), 51-56, 2016. https://doi.org/10.5755/j01.eie.22.6.17224

[38] V. Biolkova, Z. Kolka, D. Biolek, "Fully balanced voltage differencing Buffered amplifier and its applications" in 2009 52nd IEEE International Midwest Symposium on Circuits and Systems (MWSCAS), Cancun, Mexico, 2009. https://doi.org/10.1109/MWSCAS.2009.5236157

[39] J. Satansup, T. Pukkalanun, W. Tangsrirat, "Electronically tunable singleinput five-output voltage-mode universal filter using VDTAs and grounded passive elements" Circuits Syst. Signal Process., 32, 945-957, 2013. https://doi.org/10.1007/s00034-012-9492-0

[40] D. Prasad, D. R. Bhaskar, M. Srivastava, "Universal voltage-mode biquad filter using voltage differencing transconductance amplifier" Indian J. Pure \& Appl. Phys., 51, 864-868, 2013.

[41] W. Tangsrirat, "Linearly tunable CMOS voltage differencing transconductance amplifier (VDTA)" Informacije MIDEM, 49(2), 61-68, 2019. https://doi.org/10.33180/InfMIDEM2019.202

[42] O. Channumsin, W. Tangsrirat, "SITO-type high-input impedance voltagemode multifunction filter using single active element" in 2019 5th International Conference on Engineering, Applied Sciences and Technology (ICEAST), Luang Prabang, Laos, 2019. https://doi.org/10.1109/ICEAST.2019.8802603

[43] N. Roongmuanpha, T. Dumawipata, W. Tangsrirat, "Triple-input singleoutput electronically controlled voltage-mode biquadratic filter" in 2019 5th International Conference on Engineering, Applied Sciences and Technology (ICEAST), Luang Prabang, Laos, 2019. https://doi.org/10.1109/ICEAST.2019.8802540

[44] P. Moonmuang, T. Pukkalanun, W. Tangsrirat, "Voltage differencing gain amplifier-based shadow filter: a comparison study" in 2020 6th International Conference on Engineering, Applied Sciences and Technology (ICEAST), Chiang Mai, Thailand, 2020 https://doi.org/10.1109/ICEAST50382.2020.9165352

[45] N. Roongmuanpha, T. Pukkalanun, W. Tangsrirat, "Three-input one-output voltage-mode biquadratic filter using single VDBA" in 2020 8th International Electrical Engineering Congress (iEECON), Chiang Mai, Thailand, 2020. https://doi.org/10.1109/iEECON48109.2020.229503

[46] Linear Technology, "100MHz current feedback amplifier with DC gain control”, LT1228 datasheet, 1994. 